\title{
BREEDING EXPERIMENTS WITH RATS
}

\author{
PROFESSOR T. H. MORGAN
}

Colunibia University

The following experiments chiefly between the black and the roof rat were undertaken as one of a series to determine how far the Mendelian law of discontinuous inheritance applies to wild varieties and species. Most of the cases of Mendelian inheritance have been determined from domesticated forms in which the varieties seem to differ from each other in the loss of one or more characters. Until we know more about the results when wild varieties are crossed with their wild species or with other varieties, we can not safely apply Mendel's law to the process of evolution.

There are two species of house rats found in this country in addition to the common gray or Norway rat. One of these is the black rat, Mus rattus, that still exists in isolated communities in the north. It also infests, I believe, certain ports in the southern states and Central America.

The other, the roof rat or Alexandrian rat, is said to have been introduced from Mediterranean ports by ships. It is generally described as a variety of the black rat. ${ }^{1}$ The roof rat is gray, it has the ticked or barred gray hair common to most wild rodents. It may, therefore, be looked upon as the original form from which the black rat has been derived. If this is the case we might expect to find that the gray color is the dominant one and the black the recessive, especially since in the domesticated species of the Norway rat, black is recessive to gray.

To my surprise I found that in the first generation the

${ }^{1}$ The black rats used in these experiments were obtained at Amherst, Mass., through the kindness of Mr. Clarence Birdseye. I am indebted to the Carnegie Station at the Tortugas and to Dr. Stockard and to Professor Edwin Linton for obtaining and transporting the roof rats used in these experiments. 
hybrids are black whichever way the cross is made. Black is dominant to gray. In all I have thirty-two such individuals. ${ }^{2}$ These black hybrids inbred have produced one litter of four black ${ }^{3}$ and one gray. The numbers are too small to furnish conclusive data, but as far as they go they indicate that the two colors follow Mendel's law.

The roof rats are white below as is also the Norway rat, but there is a peculiar difference. In the roof rat the white hair is white to its very base, i. e., it is not ticked. In the Norway rat the ventral hair has a dark base as in most other rodents.

All attempts to cross the black rat or the roof rat with the Norway rat, or with its domesticated varieties have failed, although by putting young rats together I have had them live in harmony for a year or more. It would appear that the two species $M$. decumanus and $M$. vattus are infertile.

On the contrary as stated above $M$. vattus and $M$. alexandrimus are perfectly fertile inter se.

In respect to the ticking of the ventral hair it is interesting to note that spotted gray mice of the domesticated breeds have the hair of the white spots uncolored all the way to the base, as in the albino. I have found a wild species of brown mouse that has a white belly and the hair is ticked, i. e., it has a dark base. When such a mouse is crossed with a spotted mouse the first generation is gray with a white belly - the hair being ticked. Such mice inbred produce amongst other combinations some spotted mice. In these mice wherever a white spot extends down the sides and across the belly the region of the spot on the belly has hairs white to the base. In other words, the white spot dominates the white belly in the same way that it dominates the gray hair of the sides and back.

2 There is some variation in the color of the black hybricls of the first generation. One that was reddish black at first later became black.

${ }^{3}$ In the second generation the four black individuals, still young, show some differences in the shades of black. 
If the white belly of the roof rat turns out to be a character separable from the uniform gray coat, as I have found to be the case with white-bellied gray mice, we may expect to find in the second generation of hybrids some gray rats with a gray belly.

The chief point of theoretical interest in these results concerns the origin of the black color in the black rat. If it is produced by the loss of the ticking factor, as Castle suggests for other black rodents, it is inexplicable why the black should dominate when crossed with the ticked gray coat of the roof-rat. If, on the other hand, the rat has arisen by the black color spreading over and obscuring the ticking beneath, then we could understand how it dominates in the first generation; also why the result is different from that when the black variety of the Norway rat is crossed with a gray rat. It remains for further work to settle this point.

The common gray or Norway rat has, as stated, a white belly - the white hairs having a black base. When such a rat is bred to an albino having black (possibly gray also) as a latent character, the first generation contains only gray rats as Crampe and Doncaster have shown; but the color of the belly varies - a point that has hitherto escaped notice In some individuals the ventral hair is a slate-color, in others it is nearly white. In both the base of the hair is blackish. There appears to be an almost, perhaps a complete, gradation between white and slate-colored belly. The extremes may be accounted for as follows: The albino may carry black-bearing and graybearing germ cells. When the former unite with a graybearing germ cell of the gray Norway rat, the addition of black may cause the black base of the ventral hair to extend farther out towards the tip, making the belly slate-color. When a gray-bearing germ cell (of the albino) meets the gray-bearing germ cell of the albino, little or no change may take place in the ventral region.

Another interpretation is also possible. The albino may carry a uniform coat, $i$. e., one that gives gray (or 
slate) below instead of white. The presence of this condition may dominate in some of the first hybrids.

In addition to the points noted above it should be recorded that in nearly all of the individuals, resulting from a cross between a wild gray Norway rat and an albino, there occurs a pure white spot or streak on the belly, as other observers have recorded. The hair of these spots is white to its base. This result is obviously due to the incomplete dominance of the uniform coat. The albino in my experiments, carried, latent, not only black, but a spotted "condition," as the second generation demonstrated. The presence of this condition in the hybrids of the first generation is shown to the extent of the white ventral spot. This region of the body is, as it were, a "weak" area in which the recessive character displays itself, although elsewhere, as a rule, the spotting is suppressed. The result shows that at certain points in the pelage a recessive character may crop out in a dominant-recessive individual.

In the second generation gray, black, spotted gray, spotted black and albinos appear, as others have already shown. In the uniform gray individuals a series of types occur varying from rats with white bellies, like that of the wild gray rat, to those with a uniform slate-colored belly. The gray color itself is subject to some variation - the result depending perhaps on the condition of the black present. 